\title{
O uso do plasma convalescente no tratamento da Covid-19: Uma revisão sistemática da literatura
}

\author{
The use of convalescent plasma in the treatment of COVID-19: A systematic \\ review
}

\author{
Gabriela Dias Macedo ${ }^{1}$; Letícia Pontes Reis ${ }^{1}$; Júlia Gonçalves Faleiros Cardoso ; \\ Isadora Ávila Chagas da Silva1; Alexandre Sampaio Moura1 ${ }^{\mathbf{1 2}}$.
}

1Universidade José do Rosário Vellano (UNIFENAS BH), Campus Itapoã, Belo Horizonte, MG, Brasil.

${ }^{2}$ Faculdade Santa Casa. Belo Horizonte, MG, Brasil.

\section{Resumo}

Introdução: A pandemia pela COVID-19 se tornou uma emergência de saúde pública mundial apresentando altas taxas de transmissibilidade e um grande número de óbitos. Ademais, essa afecção possui poucas opções terapêuticas efetivas. Uma dessas opções é o plasma convalescente, medida com alto potencial terapêutico, todavia, com escassez de revisões sistemáticas sobre seu uso nessa doença. Objetivo: A finalidade do estudo foi fazer uma revisão sobre a efetividade desse tratamento na COVID-19. Metodologia: Realizou-se uma revisão sistemática de literatura sobre o uso de plasma convalescente no tratamento de pacientes com a COVID-19, com base nas plataformas de dados Pubmed e Scielo. Resultados: Foram analisados treze artigos, oito deles são série de casos, quatro relatos de casos e um ensaio clínico randomizado. Os trabalhos demonstraram que o plasma convalescente pode ser considerado um possível componente do arsenal terapêutico para o tratamento da COVID-19, apresentando pouco ou nenhum efeito adverso. Porém, a maioria dos estudos analisou a associação do plasma a outros medicamentos, o que pode confundir a estimativa do seu efeito isolado. Também, o número de pacientes estudados é ainda pequeno e o viés de seleção está presente na maior parte dos estudos. Além disso, as dosagens, o número de aplicações utilizadas e os padrões de melhora considerados nos artigos foram extremamente variáveis. Conclusão: Apesar de alguns trabalhos apontarem benefício e segurança terapêutica do plasma convalescente, existem fatores de confusão, que não permitem uma análise definitiva de sua eficácia. Para padronização e recomendação de seu uso são necessários mais estudos clínicos, preferencialmente ensaios clínicos randomizados.

Palavras-Chave: COVID-19; Plasma Convalescente; Tratamento.

Autora correspondente:

Gabriela Dias Macedo

Endereço: Rua Santa Rita Durão. 1185 apto 601 - Funcionários

Recebido em: 01/08/2020

CEP: 30140-118-Belo Horizonte (MG), Brasil.

Revisado em: 18/08/2020

Aceito em: 23/10/2020

E-mail: gabidiasgdm@hotmail.com

Publicado em: 02/03/2021 


\begin{abstract}
Introduction: The COVID-19 pandemic has become an emergency in worldwide public health presenting high transmissibility and a lot of deaths. Moreover, it's an illness with few therapy options. One of them is the convalescent plasma, a procedure with high therapeutic potential, whose systematic reviews on its uses in treating the disease are, however, scarce. Objective: The purpose of the study was to evaluate the effectiveness of this treatment in COVID-19. Methodology: A systematic review about the use of the convalescent plasma in the treatment of patients with COVID-19 was carried out based on data platforms Pubmed and Scielo. Results: Thirteen articles were analyzed, eight of which being case series, four of which case reports and one randomized clinical trial. The studies demonstrated that convalescent plasma can be a possible component of the therapy arsenal for the treatment of COVID-19, having few or none adverse effect. However, not only did the majority of the studies analyze the plasma in association with other drugs, which can confuse the estimative of its isolated effect, but also the number of studied patients was small and a selection bias is present. Furthermore, the dosage, the number of applications and the pattern of improvement in each study were variable. Conclusion: Although some papers point out the therapeutic safety as well as some benefits of convalescent plasma, there are confusing factors that don't allow a definite analysis of its efficiency. To the standardization and recommendation of its usage, more clinical studies are necessary, preferably randomized clinical trials.
\end{abstract}

Keywords: COVID-19; Convalescent Plasma; Treatment.

\section{Introdução}

O novo Coronavírus (SARS- CoV- 2) é um vírus de RNA envelopado que faz parte da família Coronaviridae. Dentre as seis espécies conhecidas que causam doença em humanos, duas delas provocam Síndrome Respiratória Aguda Grave (SARS) com altas taxas de mortalidade, quais sejam o SARS- CoV e o MERS-CoV ${ }^{1}$.

O principal meio de transmissão se dá pelas secreções respiratórias, e a doença apresenta altas taxas de transmissibilidade. Ainda faltam estudos para esclarecer completamente a fisiopatogênese, virulência e infectividade da COVID-19, fatores limitantes para determinação de um tratamento efetivo, visando à redução da letalidade ${ }^{2}$.

Atualmente, devido à ausência de tratamento específico e à necessidade mundial de evitar desfechos ruins da SARS pelo SARS-CoV-2, inúmeros medicamentos têm sido investigados e testados. Dentre eles, vale ressaltar estudos promissores com o uso de antivirais como remdesivir e o uso de corticosteroide para o manejo de pacientes graves. Em contrapartida, ainda faltam estudos que comprovem a segurança e a eficácia desses medicamentos no manejo da COVID-193.

A terapia de imunização passiva é uma ferramenta utilizada para o tratamento de doenças infecciosas, desde o século XIX, dada a ausência de medicamentos e vacinas eficazes durante surtos. Desde a gripe espanhola até a atual pandemia, passando por importantes doenças como Ebola e gripe aviária, o uso de plasma convalescente tem se apresentado como uma opção terapêutica segura em situações de emergência. Como é o caso das infecções pelo H1N1 e pelo SARSCoV-2, nas quais foram relatadas redução das taxas de mortalidade e a ocorrência de efeitos adversos leves. Ademais, o uso de plasma reduziu a necessidade de suporte ventilatório e diminuição da carga viral em infecções causadas pela influenza aviária (H5N1) .

O uso do plasma convalescente como uma das opções terapêuticas se dá pela falta de medidas efetivas para o manejo da SARS causada pela COVID-19. Atualmente, essa condição clínica tem como base de tratamento o suporte ventilatório, apresentando alto número de óbitos, que são extremamente variáveis de 
acordo com cada região mundial acometida pela pandemia ${ }^{2}$.

Essa terapia consiste em uso de plasma de um indivíduo que já foi previamente infectado pelo SARSCoV-2 e curado, produzindo anticorpos neutralizantes ao vírus. O plasma contendo os anticorpos é administrado em pacientes sintomáticos que possuem comprovação laboratorial da doença visando à redução dos sintomas, da viremia e da mortalidade ${ }^{4}$. Estudos propuseram que os mecanismos de ação dos anticorpos se baseiam na neutralização direta do vírus, inibindo sua amplificação, ativação do complemento e imunomodulação, limitando a cascata inflamatória, que, em excesso, é deletéria ao paciente ${ }^{1}$.

A realização desse trabalho se justifica, pois a pandemia pelo novo coronavírus se tornou emergência de saúde pública de interesse mundial, é necessário esforço internacional coordenado para o combate da doença5. Após análise criteriosa da literatura científica disponível, foi identificada pelos pesquisadores a escassez de revisões sistemáticas sobre o uso da terapêutica em questão, que vem se mostrando uma opção viável no manejo de pacientes acometidos pela patologia.

Portanto, este estudo teve como finalidade fazer uma revisão literária sobre a efetividade do uso do plasma convalescente no tratamento de pacientes com a COVID19, para proporcionar aos profissionais da saúde evidências atualizadas sobre uma potencial alternativa terapêutica para o manejo de pacientes críticos. Frente a tantas incertezas em relação à propedêutica dessa doença é de extrema importância para o conhecimento dos diversos recursos disponíveis.

\section{Metodologia}

Realizou-se uma revisão sistemática de literatura sobre o uso de plasma convalescente no tratamento de pacientes com a COVID-19, nas bases de dados online Pubmed e Scielo. Para estratégia de busca avançada, selecionando a opção título ou resumo, foram utilizadas as palavras-chave "Convalescent" AND "Plasma" AND "COVID-19" OR "Coronavírus", sem nenhum filtro de busca aplicado. A pesquisa foi feita levando em consideração todos os estudos que foram publicados nas bases de dados até a o dia 14 de junho de 2020.

Cada plataforma de busca foi avaliada separadamente, para identificação do número total de artigos. Após esse processo foi analisada a presença de possíveis artigos duplicados para exclusão. Na primeira etapa, de rastreamento, foi feita uma triagem por meio da leitura de título e de resumo, para selecionar de forma geral os estudos que se enquadravam no tema principal dessa revisão. Na segunda etapa, de elegibilidade, foi feita a cautelosa leitura na íntegra dos textos para a escolha daqueles que se encaixavam nos critérios de inclusão e exclusão pré-definidos. Além disso, as referências bibliográficas dos artigos selecionados foram checadas para identificar estudos adicionais relevantes, que poderiam ter sido omitidos com a estratégia de busca supracitada.

Todos esses passos foram realizados e checados por meio de uma dupla de revisores, de maneira independente, para a redução do risco do viés da avaliação individual. Conflitos de opiniões foram solucionados por meio do julgamento de um terceiro revisor. O processo de seleção de artigos foi descrito de forma detalhada na FIGURA 1, por meio da ferramenta "PRISMA 2009 Flow Diagram".

Foram utilizados os seguintes critérios de inclusão: Estudos em seres humanos, envolvendo o uso de plasma convalescente, no manejo de pacientes diagnosticados com COVID-19, independentemente da concomitância de outras comorbidades. Já os critérios de exclusão foram: Uso de plasma convalescente única e exclusivamente em outras doenças que não a COVID-19; Estudos que avaliaram apenas o procedimento de doação do plasma convalescente para pacientes portadores da COVID-19; Artigos de revisão de literatura, adendos, editoriais, carta para periódicos, comentários de especialistas, protocolo de ensaios clínicos não finalizados, dentre outros formatos que não avaliam o uso da terapia com o plasma convalescente em seres humanos.

\section{Resultados}



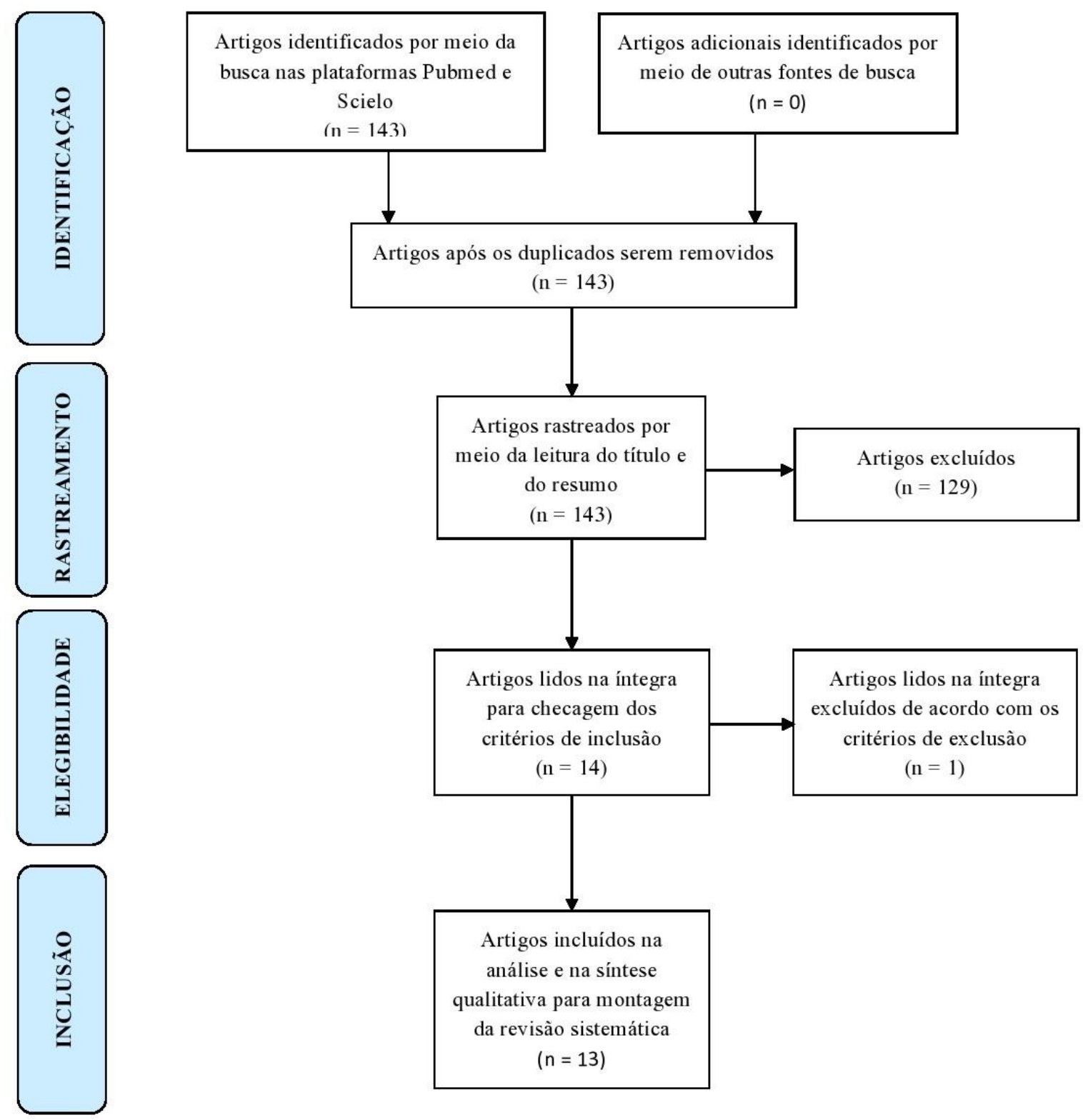

FIGURA 1 - Processo de seleção dos artigos. Prisma Flow Diagram descrevendo o passo a passo do procedimento de seleção dos artigos utilizados no presente estudo. 
TABELA 1 - Análise dos artigos selecionados

\begin{tabular}{|c|c|c|c|c|c|}
\hline & Nome do artigo & Metodologia & $\begin{array}{c}\text { Dose de plasma } \\
\text { convalescente }\end{array}$ & $\begin{array}{c}\text { Medicamentos } \\
\text { associados }\end{array}$ & Desfechos \\
\hline 1 & $\begin{array}{c}\text { Anti-SARS-CoV- } 2 \text { virus antibody } \\
\text { levels in convalescent plasma of six } \\
\text { donors who recovered from COVID } \\
19\end{array}$ & $\begin{array}{l}\text { Relato de caso de mulher } \\
\text { de } 64 \text { anos }\end{array}$ & $200 \mathrm{~mL}$ & $\begin{array}{l}\text { Não usa outros } \\
\text { medicamentos }\end{array}$ & $\begin{array}{l}\text { Melhora da contagem dos linfócitos, da função } \\
\text { renal e hepática e diminuição dos sintomas de } \\
\text { tosse e febre, além de desmame da ventilação } \\
\text { mecânica no dia } 11 \text { após o uso do plasma. }\end{array}$ \\
\hline 2 & $\begin{array}{l}\text { Convalescent (Immune) plasma } \\
\text { treatment in a myelodysplastic } \\
\text { COVID-19 patient with } \\
\text { disseminated tuberculosis }\end{array}$ & $\begin{array}{l}\text { Relato de caso de } 1 \\
\text { paciente }\end{array}$ & $400 \mathrm{~mL}$ em 2 dias & Antivirais, antibióticos & $\begin{array}{l}\text { Melhora do quadro clínico após a segunda dose } \\
\text { de plasma. Após CP: teste SARS-CoV-2 IgG } \\
\text { positivo (Título de } 5,1 \text { ) e negativação do segundo } \\
\text { teste de PCR para SARS-CoV-2. }\end{array}$ \\
\hline 3 & $\begin{array}{c}\text { Effectiveness of convalescent } \\
\text { plasma therapy in severe COVID- } \\
19 \text { patients }\end{array}$ & $\begin{array}{l}\text { Série de casos com } 10 \\
\text { pacientes em condições } \\
\text { clínicas graves }\end{array}$ & $200 \mathrm{~mL}$ & $\begin{array}{l}\text { Antivirais, antibióticos } \\
\text { e corticoesteroides }\end{array}$ & $\begin{array}{c}\text { Melhora dos sintomas, aumento da saturação de } \\
\text { oxigênio, com redução da necessidade de } \\
\text { suplementação. Aumento na contagem de } \\
\text { linfócitos, redução de proteína C reativa, TGO e } \\
\text { TGP. Aumento nos títulos de anticorpos } \\
\text { neutralizantes em } 5 \text { pacientes, uma vez que em } 4 \\
\text { se mantiveram iguais. } 1 \text { paciente não teve a } \\
\text { contagem feita. A carga viral no plasma se } \\
\text { reduziu em } 7 \text { pacientes. }\end{array}$ \\
\hline 4 & $\begin{array}{l}\text { Effect of Convalescent Plasma } \\
\text { Therapy on Time to Clinical } \\
\text { Improvement in Patients With } \\
\text { Severe and Life-threatening } \\
\text { COVID-19: A Randomized Clinical } \\
\text { Trial }\end{array}$ & $\begin{array}{l}\text { Ensaio clínico } \\
\text { randomizado, aberto, } \\
\text { multicêntrico com } 103 \\
\text { pacientes }\end{array}$ & 4 a $13 \mathrm{~mL}$ por $\mathrm{Kg}$ & $\begin{array}{l}\text { Antivirais, antibióticos, } \\
\text { corticoesteroides, } \\
\text { imunoglobulina, } \\
\text { fitoterápicos, } \\
\text { antifúngico. }\end{array}$ & $\begin{array}{c}\text { Sem diferença na mortalidade, sem diferença na } \\
\text { redução do tempo para alta dos pacientes e não } \\
\text { houve redução do tempo para melhora clínica. O } \\
\text { grupo de plasma convalescente teve carga viral } \\
\text { negativada em menor tempo. }\end{array}$ \\
\hline 5 & $\begin{array}{l}\text { Effect of Convalescent Plasma } \\
\text { Therapy on Viral Shedding and } \\
\text { Survival in COVID-19 Patients }\end{array}$ & $\begin{array}{l}\text { Série de casos com } 21 \\
\text { pacientes }\end{array}$ & $300 \mathrm{~mL}$. & Não relatado & $\begin{array}{l}\text { Interrupção do aumento da carga viral e aumento } \\
\text { na sobrevida. No entanto, sem interferência na } \\
\text { redução de mortalidade. }\end{array}$ \\
\hline 6 & $\begin{array}{c}\text { Epidemiological and clinical } \\
\text { characteristics of discharged } \\
\text { patients infected with SARS-CoV-2 } \\
\text { on the Qinghai plateau }\end{array}$ & $\begin{array}{l}\text { Série de casos com } 18 \\
\text { pacientes, e apenas } 4 \\
\text { fizeram o uso de plasma } \\
\text { convalescente }\end{array}$ & $50 \mathrm{~mL}, 2$ vezes & $\begin{array}{c}\text { Antivirais, antibióticos, } \\
\text { corticoesteroides, } \\
\text { terapias } \\
\text { imunorreguladoras, } \\
\text { medicina tradicional } \\
\text { chinesa }\end{array}$ & $\begin{array}{c}\text { Melhora nos padrões observados pela TC, pela } \\
\text { gasometria arterial e melhora da sintomatologia } \\
\text { clínica. }\end{array}$ \\
\hline 7 & $\begin{array}{c}\text { Successful Treatment of a } \\
\text { centenarian with coronavirus } \\
\text { disease } 2019 \text { using convalescent } \\
\text { plasma }\end{array}$ & $\begin{array}{l}\text { Relato de caso de um } \\
\text { paciente de } 100 \text { anos }\end{array}$ & $\begin{array}{l}\text { Primeira dose: } 200 \\
\text { mL. } \\
\text { Segunda dose: } 100 \\
\text { mL }\end{array}$ & $\begin{array}{l}\text { Sintomáticos (Não cita } \\
\text { quais). }\end{array}$ & $\begin{array}{l}\text { Melhora dos sintomas de tosse e dispneia, } \\
\text { diminuição da carga viral no paciente. }\end{array}$ \\
\hline
\end{tabular}


8 The use of convalescent plasma therapy and remdesivir in the successful management of a critically ill obstetric patient with novel coronavirus 2019 infection: a case report

9 Treatment of Coronavirus Disease 2019 (COVID-19) Patients with Convalescent Plasma

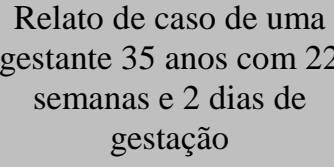

Relato de caso de uma gestante 35 anos com 22 semanas e 2 dias de gestação

Série de casos com 25 pacientes

\section{Não cita a dose} utilizada

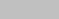

antimaláricos, heparina

$300 \mathrm{~mL}$ de plasma Imunomoduladores,

convalescente.

Apenas 1 paciente

recebeu nova dose

$$
\text { após } 6 \text { dias }
$$

10 Treatment with convalescent plasma for COVID-19 patients in

Wuhan, China

Série de casos com 6 pacientes

Pelo menos 1 ciclo de

$200 \mathrm{~mL}$ (Os números

de ciclos variaram

entre os pacientes).

11 Treatment with convalescent plasma for critically ill patients

with severe acute respiratory

Série de casos com 4

Paciente 1: $200 \mathrm{~mL}+$ pacientes

$400 \mathrm{~mL}+300 \mathrm{~mL}$

Paciente 2: $200 \mathrm{~mL}$.

Paciente 3: $2400 \mathrm{~mL}$

no total, divididos em

$$
8 \text { dias. }
$$

\begin{tabular}{|c|c|c|}
\hline 12 & $\begin{array}{c}\text { Treatment of } 5 \text { Critically Ill } \\
\text { Patients With COVID-19 With } \\
\text { Convalescent Plasma }\end{array}$ & $\begin{array}{c}\text { Série de casos com } 5 \\
\text { pacientes em condições } \\
\text { clínicas graves }\end{array}$ \\
\hline
\end{tabular}

Paciente 4: $300 \mathrm{~mL}$

13 Use of Convalescent Plasma

Therapy in Two COVID-19

Patients with Acute Respiratory

Série de casos com 2 pacientes

Distress Syndrome in Korea

\section{Melhora clínica de $76 \%$ e alta hospitalar de $44 \%$}

corticoesteroides,

antimaláricos,

antibióticos, antivirais dos pacientes, após 14 dias da transfusão.

Redução da proteína C reativa. Nenhum aumento significativo de enzimas hepáticas.
Antibióticos,

de baixo peso,

corticoesteroides

antivirais

Melhora dos sintomas respiratórios da paciente com desmame da ventilação invasiva, melhora progressiva do padrão respiratório após catete nasal. Enzimas hepáticas normalizadas, sem alterações renais, melhora da tosse e da febre.

$\begin{array}{cc}\text { Não relatado } & \begin{array}{r}\text { Melhora clínica, laboratorial e radiográfica em } \\ \text { todos os pacientes. }\end{array} \\ \begin{array}{c}\text { Antivirais, } \\ \text { antifúngicos, } \\ \text { antibióticos, }\end{array} & \begin{array}{c}\text { Melhoria do padrão respiratório, melhora } \\ \text { radiográfica das imagens de tórax, diminuição } \\ \text { dos sintomas de tosse e febre e PCR indetectável. }\end{array}\end{array}$

imunomoduladores corticoesteroides,
Metilprednisolona, antivirais.
Normalização da temperatura corporal, redução do score SOFA, aumento na relação $\mathrm{PaO}^{2} / \mathrm{FiO}^{2}$, negativação da carga viral, aumento dos anticorpos neutralizantes, redução da lesão pulmonar à TC.

Melhora significativa clínico-laboratorial,

Antimaláricos

antivirais e

corticoesteroides apresentando negativação dos títulos de SARSCoV-2.

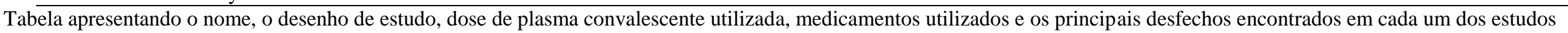

analisados e discutidos ao longo da atual revisão de literatura. 


\section{Discussão}

A presente revisão sistemática teve como base a análise de treze artigos, oito deles são série de casos, quatro relatos de casos e um ensaio clínico randomizado. A diversidade dos estudos analisados na literatura, bem como a heterogeneidade dos seus participantes, não permitiu a realização de uma metanálise. Os trabalhos demonstraram que o plasma convalescente pode ser considerado como um possível recurso terapêutico para o tratamento dos pacientes infectados pelo novo SARSCoV-2, pois, atualmente a COVID-19 é uma doença que apresenta diversas características ainda desconhecidas e sem formas de tratamento comprovadamente eficazes.

Após a descoberta do novo SARS-CoV-2, no final de 2019, pesquisadores de diversos países iniciaram a procura incessante por um tratamento eficaz para a doença que, no final de julho de 2020, já havia feito 668.910 vítimas em todo mundo ${ }^{6}$. O uso do plasma convalescente, que já se mostrou eficaz no combate de doenças anteriormente, é uma das opções que tem sido amplamente estudada no momento.

Dois pacientes acompanhados em serviços hospitalares da China e dos Estados Unidos apresentaram uma diminuição na taxa de vírus circulante no sangue após o uso do tratamento com o plasma convalescente, uma vez que o primeiro deles, utilizou, em um paciente de 100 anos de idade, uma primeira dose de $200 \mathrm{~mL}$, seguida de outra dose de $100 \mathrm{~mL}$. Enquanto que, para a segunda paciente, gestante de 22 semanas, os autores não relataram a dosagem usada do plasma convalescente. Além disso, os dois pacientes tiveram uma resolução mais rápida dos sintomas como febre e insuficiência respiratória. Porém, em ambos os relatos de caso houve o uso concomitante de diversos outros medicamentos, incluindo sintomáticos, antibióticos, antimaláricos, corticoides e antivirais ${ }^{7,8}$.

O tratamento com plasma convalescente também se mostrou eficaz quando analisado o desfecho de um paciente portador de tuberculose e mielodisplasia que apresentou sintomas da COVID-19 e positivação no exame laboratorial. Após o uso do plasma, houve uma melhora clínica significativa, além de não detecção do RT-PCR na segunda dosagem e desenvolvimento de anticorpos IgG. A melhora da função renal e hepática e o desmame precoce da ventilação mecânica foram os principais resultados observados em uma paciente de 64 anos que recebeu $200 \mathrm{~mL}$ de plasma convalescente, sem que houvesse tratamento concomitante com outras drogas durante o período da internação ${ }^{9,10}$.

Uma série de casos realizada com 25 pacientes na China demonstrou que o uso do plasma convalescente no combate ao COVID-19 é promissor. Dentre todos os pacientes tratados e acompanhados, houve melhora dos sintomas em cerca de $76 \%$ e alta hospitalar após duas semanas da transfusão em $44 \%$ deles. Porém, foi feito o uso de outros medicamentos pelos mesmos pacientes, durante o mesmo período, incluindo imunomoduladores, corticoesteroides, antimaláricos, antibióticos e antivirais $^{11}$.

Por sua vez, na série de casos que contou com uma amostragem de 21 pacientes que fizeram a terapia com plasma convalescente, foram observados indícios de que esse tratamento diminuiu a carga viral e aumentou a sobrevida dos pacientes, porém, reduções nas taxas de mortalidade não se mostraram presentes. Os autores desse estudo não relataram se foi feito o uso de outros medicamentos em conjunto com o plasma convalescente ${ }^{12}$.

O uso de $200 \mathrm{~mL}$ de plasma convalescente, uma única vez, em pacientes hospitalizados e com sintomas e repercussões graves da doença, foi o tratamento utilizado por uma série de casos que contou com 10 pacientes durante o estudo, uma vez que estes fizeram o uso concomitante de outras drogas, como corticoide, antivirais e antibióticos. Ao passo que em outra série de casos com 4 pacientes, os pesquisadores utilizaram doses que variavam entre $200 \mathrm{~mL}$ e $300 \mathrm{~mL}$, e, alguns pacientes fizeram o uso do plasma em somente uma ocasião e outros em oito ocasiões diferentes. Todos os pacientes tiveram associação com outras drogas em seus tratamentos. Ambos os estudos demonstraram uma melhora no padrão respiratório dos pacientes, diminuição da carga viral ou, até mesmo, sua negativação e, no primeiro estudo, melhora da função hepática dos pacientes ${ }^{13,14}$. 
A melhora do acometimento pulmonar nas imagens tomográficas foi um dos desfechos mais relevantes da série de casos de 5 pacientes em estado crítico, que fizeram o uso de $400 \mathrm{~mL}$ de plasma convalescente em conjunto com corticoides e antivirais. Já outra série de casos analisada, fez o uso de $200 \mathrm{~mL}$ de plasma convalescente em ciclos variáveis entre os 6 pacientes participantes, com melhora clínica e radiográfica em todos eles. Porém, não houve relatos sobre o uso de outros medicamentos concomitantes ${ }^{15,16}$.

Quatro pacientes, dentre os 18 analisados em uma série de casos realizada na China, fizeram o uso de $50 \mathrm{~mL}$ de plasma convalescente em duas aplicações distintas, concomitantemente com antivirais, antibióticos, corticoides, medicina chinesa e imunorreguladores, apresentando melhora clínica, laboratorial e melhora do acometimento pulmonar observado pela TC de tórax. A negativação dos títulos de RT-PCR e a melhora dos sintomas respiratórios foram os resultados encontrados na série de casos com 2 pacientes que fizeram o uso de 500 $\mathrm{mL}$ de plasma convalescente em duas aplicações, além de antimaláricos, antivirais e corticoides ${ }^{17,18}$.

Dentre as séries de casos e os relatos de casos analisados, os efeitos adversos citados foram o aumento do dímero-D em um paciente que recebeu $200 \mathrm{~mL}$ de plasma convalescente e o desenvolvimento de uma mácula avermelhada em face. Porém, os demais estudos não relataram presença de efeitos adversos nos pacientes ou não os citaram no desenvolvimento de suas conclusões $^{10,13}$.

Deve-se levar em conta que as dosagens e o número de aplicações utilizadas foram extremamente variáveis entre os estudos. Esse fator dificulta a realização de uma análise criteriosa dos reais benefícios do plasma convalescente nos pacientes diagnosticados com COVID19, bem como o estabelecimento de um protocolo específico que padronize a recomendação de seu uso. Houve também uma variação entre os padrões de melhora esperados por cada um dos trabalhos, o que impede realizar uma observação mais fidedigna dos reais benefícios adquiridos, após o uso do plasma convalescente.
A diminuição da carga viral e sua negativação precoce, quando comparada ao grupo controle que não realizou o uso do plasma em seu tratamento foi o desfecho principal encontrado no ensaio clínico randomizado analisado. Esse estudo, que contou com 103 pacientes e fez o uso concomitante de diversos medicamentos (Antivirais, antibióticos, corticoesteroides, imunoglobulina, fitoterápicos, antifúngicos), não relatou diminuição no tempo de internação dos pacientes que fizeram o uso do plasma, como também não houve a diminuição da mortalidade ao serem comparados aos pacientes os quais não fizeram o uso deste tratamento. Os efeitos colaterais foram observados em uma pequena parcela dos pacientes e incluíram o quadro de dispneia severa, febre e rash cutâneo, após a realização da transfusão do plasma convalescente ${ }^{19}$.

A principal limitação do ensaio clínico randomizado supracitado foi o encerramento precoce da pesquisa, após discussão com o Comitê de Ética responsável pelo acompanhamento do estudo. Este entendeu que os resultados encontrados não apresentavam grande relevância clínica, além de ter havido uma diminuição dos casos diagnosticados de COVID-19, em Wuhan, durante esse período, o que levou a uma impossibilidade de aumentar a amostragem dos pacientes $\operatorname{analisados}^{19}$.

A utilização do plasma convalescente para o tratamento da COVID-19, na sua maioria em pacientes graves, demonstrou indícios de ser eficaz, principalmente, na redução da carga viral circulante e na melhoria do padrão respiratório de seus usuários. Com poucos ou quase nenhum efeito adverso foram descritos ao longo dos estudos e essa terapêutica também apresentou bom perfil de segurança. Porém a maior parte dos estudos analisados realizou o uso de outros medicamentos, como corticoides, antibióticos e antivirais em associação com o plasma convalescente, podendo se tornar um fator de confusão durante a análise dos dados.

Deve-se levar em consideração também a heterogeneidade do perfil dos pacientes analisados, com grande parte dos participantes apresentando casos graves da doença. É extremamente relevante levar em conta essa 
informação durante as análises dos benefícios do plasma convalescente na COVID-19. O viés de seleção pode interferir nos resultados encontrados, o que faz os achados não serem necessariamente aplicáveis para todos os doentes. O uso do plasma em casos leves e moderados doença necessita de maiores estudos, para se avaliarem os possíveis benefícios desse tratamento em outros grupos de pacientes.

\section{Conclusão}

O uso terapêutico de plasma convalescente para pacientes com a COVID-19 ainda não possui evidências científicas de alta qualidade e suficientes que comprovem sua eficácia. Apesar de alguns trabalhos corroborarem a favor do seu potencial benefício e segurança, existem diversos fatores de confusão na literatura avaliada que não permitem uma análise específica e padronizada das verdadeiras vantagens de seu uso. O presente estudo teve diversas limitações em decorrência da heterogeneidade encontrada. Dessa maneira, são necessários mais estudos, como ensaios clínicos randomizados, para se confirmar e definir melhor os benefícios dessa abordagem terapêutica no tratamento da COVID-19.

\section{Declaração de conflito de interesses}

Os autores declararam que não há nenhum conflito de interesses envolvido no presente estudo.

\section{Referências}

1. ROJAS, M., RODRÍGUEZ, Y., MONSALVE, D., AMPUDIA, Y., CAMACHO, B., GALLO, J., et al. Convalescent plasma in Covid-19: Possible mechanisms of action. Autoimmunity Reviews, Colombia, v.19, n.7, 102554,2020.

2. LANA, R., COELHO, F., GOMES, M., CRUZ, O., BASTOS, L., VILELA, D., CODEÇO, C. Emergência do novo coronavírus (SARS-CoV2) e o papel de uma vigilância nacional em saúde oportuna e efetiva. Cadernos de Saúde

Pública, Brasil, v.36, n.3, e00019620, 2020.
3. JEAN, S., LEE, P., HSUEH, P., Treatment options for COVID-19: The reality and challenge. Journal of Microbiology, Immunology and Infection, Taiwan, v.53, n.3, p.436-443, 2020.

4. RAJENDRAN, K., KRISHNASAMY, N., RANGARAJAN, J., RATHINAM, J., NATARAJAN, M., RAMACHANDRAN, A. Convalescent plasma transfusion for the treatment of COVID-19: Systematic review. Journal of Medical Virology, India, 10.1002/jmv.25961, 2020.

5. ZHAI, P., DING, Y., WU, X., LONG, J., ZHONG, Y., LI, Y. The epidemiology, diagnosis and treatment of COVID-19. International Journal of Antimicrobial Agents, China, v.55, n.5, e105955, 2020.

6. WORLD HEALTH ORGANIZATION. Coronavirus disease 2019 (Covid-19) Situation report - 193 (July, 31, 2020). Disponível em: <https://www.who.int/emergencies/diseases/nov el-coronavirus-2019/situation-reports> Acesso em: 31 de julho de 2020 .

7. ANDERSON, J., SCHAUER, J., BRYANT, S., GRAVES, C. The use of convalescent plasma therapy and remdesivir in the successful management of a critically ill obstetric patient with novel coronavirus 2019 infection: A case report. Case Reports in Women's Health, Estados Unidos, v.27, e00221, 2020.

8. KONG, Y., CAI, C., LING, L. WU, M., WU, Y., ZHANG, W. Successful treatment of a centenarian with coronavirus disease 2019 (COVID-19) using convalescent plasma. Transfusion and Apheresis Science, China, e102820, 2020. 
9. ÇINAR, O., SAYINALP, B., KARAKULAK,

A., KARATAS, A., VELET, M., INKAYA, A., et al. Convalescent (immune) plasma treatment in a myelodysplastic COVID-19 patient with disseminated tuberculosis. Transfusions and

Apheresis Science, Turquia, e102821, 2020.

10. ZHANG, L., PANG, R., XUE, X., BAO, J., YE, S., DAI, Y.,et al. Anti-SARS-CoV-2 virus antibody levels in convalescent plasma of six donors who have recovered from COVID-19. Aging, Estados Unidos, v.12, n.8, p.6536-6542, 2020.

11. SALAZAR, E., PEREZ, K., ASHRAF, M., CHEN, J., CASTILLO, B., CHRISTENSEN, P., et al. Treatment of Coronavirus Disease 2019 (COVID-19) Patients with Convalescent Plasma. The American Journal of Pathology, Estados Unidos, v. 190, n. 8, p. 1680-1690, 2020.

12. ZENG, Q., YU, Z., GOU, J., LI, G., MA, S., ZHANG, G., et al. Effect of Convalescent Plasma Therapy on Viral Shedding and Survival in Patients With Coronavirus Disease 2019. The Journal of Infectious Disease, Estados Unidos, v.222, n.1, p. 38-43, 2020.

13. DUAN, K., LIU, B., LI, C., ZHANG, H., YU, T., QU, J., et al. Effectiveness of convalescent plasma therapy in severe COVID-19 patients. Proceedings of the National Academy Sciences of the USA, Estados Unidos, v.117, n.17, p.9490-9496, 2020.

14. ZHANG, B., LIU, S., TAN, T., HUANG, W., DONG, Y., CHEN, L., et al. Treatment With Convalescent Plasma for Critically Ill Patients With Severe Acute Respiratory Syndrome Coronavirus 2 Infection. Chest Journal, Estados Unidos, v.158, n.1, p.e9-e13, 2020.
15. SHEN, C., WANG, Z., ZHAO, F., YANG,Y., LI, J., YUAN, J., et al. Treatment of 5 Critically Ill Patients With COVID-19 With Convalescent Plasma. JAMA Journal, Estados Unidos, v.323, n.16, p.1582-1589, 2020.

16. YE, M., FU, D., REN, Y., WANG, F., WANG, D., ZHANG, F., et al. Treatment with convalescent plasma for COVID-19 patients in Wuhan, China. Journal of Medical Virology, China, 10.1002/jmv.25882, 2020.

17. XI, A., ZHUO, M., DAI, J., DING, Y., MA, X., MA, X., et al. Epidemiological and clinical characteristics of discharged patients infected with SARS-CoV-2 on the Qinghai plateau. Journal of Medical Virology, China, 10.1002/jmv.26032, 2020.

18. AHN, J., SOHN, Y., LEE, S., CHO, Y., HYUN, J., BAEK, Y., et al. Use of Convalescent Plasma Therapy in Two COVID-19 Patients with Acute Respiratory Distress Syndrome in Korea. Journal of Korean Medical Science, Coreia, v.35, n.14, p.e149, 2020.

19. LING, L., ZHANG, W., HU, Y., TONG, X. Effect of Convalescent Plasma Therapy on Time to Clinical Improvement in Patients With Severe and Life-threatening COVID-19: A Randomized Clinical Trial. JAMA Journal, China, e2010044, 2020. 